\title{
Analisis Performansi Antara Apache \& Nginx Web Server dalam Menangani Client Request
}

\author{
Albert Yakobus Chandra \\ Universitas Mercu Buana Yogyakarta \\ e-mail: albert.ch@mercubuana-yogya.ac.id \\ Diajukan: 16 November 2019; Direvisi: 27 November 2019; Diterima: 28 November 2019
}

\begin{abstract}
Abstrak
Dalam keberadaan World Wide Web (WWW), web server menjadi salah satu faktor penting agar sebuah website dapat berjalan dengan baik dan melayani kebutuhan pengguna web tersebut. Web server yang tepat digunakan untuk sebuah sistem website maka dapat dipastikan website tersebut selalu dapat berjalan dengan baik. Saat ini banyak pilihan web server yang dapat digunakan untuk menjalankan sistem website, dua yang paling populer digunakan adalah Apache dan Nginx web server. Penelitian ini akan melakukan pengujian pada kedua web server tersebut untuk mengetahui salah satu web server yang terbaik dalam menyelesaikan client request. Pengujian yang dilakukan mengggunakan tools Apache Bench untuk melakukan benchmarking dari sisi banyak nya client request yang bervariasi mulai dari 100 request sampai dengan 1000000 request dan waktu yang dibutuhkan untuk menyelesaikan request tersebut. Hasil uji pada penelitian ini memberikan hasil benchmarking yang menunjukkan bahwa dari sisi penggunaan waktu, nginx menggunakan waktu lebih sedikit daripada Apache dalam menyelesaikan client request.
\end{abstract}

Kata kunci: Web server, Website, Benchmarking, Nginx, Apache.

\section{Abstract}

In existence of the World Wide Web (WWW), web server is one of the required important factors for a website could run well and serve the user of the website. The right web server used for a website then the website could always run well without any problem. There are currently many web servers that could be used to run a website system, two of them that most popular is Apache and Nginx web server. This research will test the two web servers to find out which one web server is the best at response to the client request. The test will be using Apache Bench tool to carried out benchmark from the variated client request start from 100 request to 1000000 request and how many times that used to complete the request. The test result of this study provides the benchmark result which is show that Nginx using more less time in completing client request rather than apache.

Keywords: Web server, Website, Benchmarking, Nginx, Apache.

\section{Pendahuluan}

Keberadaan World Wide Web (WWW) sebagai media perantara untuk menyajikan hypermedia melalui jaringan internet telah menjadi sebuah kebutuhan. Di mana pertumbuhan pengguna telah menunjukkan peningkatan yang eksponensial dalam beberapa tahun terakhir. Beberapa penelitian menunjukkan bahwa lebih dari $75 \%$ lalu lintas data yang mengalir melalui jaringan internet didominasi oleh data Hypertext Transfer Protocol (HTTP) [1]. Oleh karena hal tersebut maka perencanaan dan penyediaan sumber daya web server untuk melayani permintaan berbasis HTTP tersebut menjadi hal yang sangat penting [2].

Dengan paradigma layanan WWW, maka layanan yang diberikan kepada pengguna (end user) akan berbasis pada paradigma client-server. Client adalah sisi aplikasi yang akan melakukan permintaan (request) ke server, permintaan dari client ini dapat berupa objek berbentuk teks, dokumen (file), video, audio, database, query, dan lain-lain. Sedangkan server adalah sisi aplikasi yang akan merespons permintaan dari client tersebut dan menyajikan data sesuai dengan request tersebut [2][3].

Server sendiri dalam tugasnya merespons permintaan dari client dibutuhkan web server untuk mengolah permintaan tersebut sebelum mengirimkan kembali jawaban yang disebut response. Apache, Nginx (Engine-x), LightHTTPD, Hiawata, Cherokee, Apache Tomcat merupakan contoh dari aplikasiaplikasi web server yang digunakan di dunia [4]. Berdasarkan survei yang dilakukan oleh Web Technology 
Surveys, Apache dan Nginx merupakan dua aplikasi web server yang paling banyak digunakan. Di mana Apache memiliki persentase kegunaan sebanyak 44,2\% dibandingkan dengan Nginx yang memiliki persentase sebanyak $41,1 \%[5]$.

Beberapa penelitian sebelumnya dalam hal menguji web server seperti penelitian yang berjudul "Analisis Web Server untuk pengembangan Hosting Server Institusi: Pembandingan Kinerja Web Server Apache dan Nginx" hasil dari penelitian ini menyatakan bahwa Apache lebih unggul dibandingkan Nginx dari sisi transfer rate dan connection time [6]. selanjutnya penelitian berjudul "Analisis Perbandingan Performa Web Server Apache dan Nginx Menggunakan HTTPERF Pada VPS Dengan Sistem Operasi CentOS" hasil dari penelitian ini menyatakan bahwa Nginx lebih unggul dalam merespons pada subjek web statis sedangkan Apache lebih unggul dalam segi bandwidth [7].

Berbeda dari penelitian yang sudah pernah dilakukan sebelumnya penelitian ini akan melakukan pengujian antara dua web server yang paling banyak digunakan yaitu Apache dan Nginx [5] untuk mengetahui web server mana yang terbaik di antara kedua web server tersebut dalam memberikan response terhadap request dari client. Metode komparasi yang digunakan pada penelitian ini adalah benchmark test menggunakan tool dari Apache Bench di mana tool ini dapat mengukur bagaimana kinerja dari web server yang digunakan dan berapa banyak waktu yang digunakan dari request per second yang mampu di serving oleh web server yang digunakan.

Pengujian kedua web server ini dilakukan dengan melakukan setup dan installation Apache dan Nginx pada Hardware Environment yang sama yaitu Dell PowerEdge R630, Xeon E5-2620, dengan menggunakan Proxmox VE sebagai Virtual Environment dan sistem operasi CentOS 7. Selanjutnya Apache Bench dijalankan untuk melakukan benchmarking dengan jumlah request dan beban request yang bervariasi mulai 100 request hingga 1000000 request.

\section{Web Server dan Bechmarking Tools}

\subsection{Apache Web Server}

Apache Web Server merupakan unix-based web server, Apache awalnya dikembangkan berbasis kode pada NCSA HTTPD 1.3 yang kemudian diprogram ulang menjadi sebuah web server yang paling banyak digunakan saat ini. Apache kini menjadi web server yang paling populer dan banyak digunakan lebih dari $42 \%$ dari berbagai domain website yang ada di internet [5]. Apache memiliki fitur yang sangat lengkap mulai dari performa yang tinggi, fungsionalitas, efisiensi, serta kecepatan. Apache juga merupakan web server berbasis open source [8].

\subsection{Nginx Web Server}

Nginx atau biasa disebut "Engine-x", adalah open source web server[9]. Nginx selain digunakan sebagai web server juga memiliki fitur untuk digunakan sebagai reverse proxy, HTTP cache, dan load balancer[10]. Nginx dibuat oleh Igor Sysoev dan dirilis ke publik pada bulan Oktober 2004. Saat awal dirilis Igor meyakinkan publik bahwa Nginx dapat menjadi jawaban untuk mengatasi permasalahan yang ada pada saat itu yaitu permasalahan performa web server jika memiliki koneksi aktif lebih dari 10.000 koneksi secara bersamaan. Nginx menawarkan penggunaan memori yang lebih rendah dibandingkan web server lainnya dan juga beberapa fitur seperti: reverse proxy, IPv6, load balancing, FastCGI support, web sockets, handling static files, TLS/SSL.

\subsection{Apache Bench}

Apache Bench adalah sebuah tool dari Apache organization yang digunakan untuk mengukur performansi pada Hypertext Transfer Protocol (HTTP) web server. Tool ini digunakan untuk menghitung berapa banyak request per second yang dapat di layani oleh web server yang digunakan. Beberapa fitur dari Apache Bench seperti: open source, simple command line, platform independent, load and performance test, not extensible. Apache Bench dapat digunakan untuk menguji performa dari web server dengan berbagai batasan pengujian seperti transfer rate dan request per second.

\subsection{CentOS}

CentOS (Community Enterprise Operating System) merupakan sebuah sistem operasi berbasis Linux yang saat ini paling populer digunakan sebagai sistem operasi dari sebuah server. Centos menyediakan platform pada skala enterprise secara free (tidak berbayar) [11]. CentOS dasarnya dibuat dari source code Red Hat Enterprise, software ini dirilis di bawah General Public License (GPL) yang selanjutnya dikembangkan oleh komunitas yang disebut CentOS Project. 


\subsection{Container-Based Virtualization}

Container-based virtualization adalah langkah terbaik dan mudah untuk membuat virtual user space [12], ini dilakukan dengan membagi kernel dari sistem operasi utama (host). User space dari sistem operasi utama atau host dibagi menjadi isolated user space yang disebut container. Model container ini tidak perlu menjalankan sistem operasi tamu (guest) dan virtual machine untuk setiap virtualized environment, sehingga model container ini memiliki kelebihan yaitu overhead yang lebih kecil dibandingkan dengan metode hypervisor-based. Selain itu container-based virtualization dapat memberikan user space yang lebih besar [12]. Container-based virtualization ini digunakan sebagai container untuk menjadi tempat yang akan menjalankan sistem operasi, web server, dan benchmarking tools.

\section{Metode Penelitian}

Metode penelitian yang digunakan pada penelitian ini adalah metode eksperimen, yaitu metode yang bertujuan untuk menguji pengaruh suatu variabel terhadap variabel lain, atau menguji hubungan sebab akibat antara variabel yang satu dengan lainnya. Metode penelitian eksperimen memiliki perbedaan yang jelas dibanding dengan metode penelitian lainnya, yaitu adanya pengontrolan terhadap variabel penelitian dan adanya pemberian perlakuan terhadap kelompok eksperimen [13][14]. Jalannya penelitian dapat dilihat pada gambar diagram jalan penelitian berikut ini:

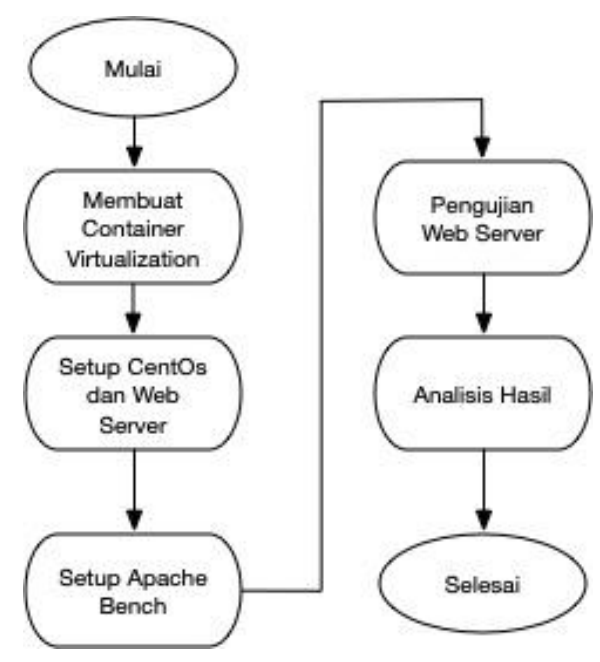

Gambar 1. Diagram jalannya penelitian.

\section{Hasil dan Pembahasan}

Berdasarkan diagram jalannya penelitian maka untuk melakukan analisis performansi pada web server dilakukan dengan langkah-langkah berikut:

\subsection{Membuat Container Virtualization}

Container virtualization digunakan sebagai virtual space dari sebuah server, virtual space ini digunakan untuk menjalankan sistem operasi, web server, dan juga Apache Bench yang merupakan tool untuk pengujian web server. Sistem aplikasi untuk membuat Container ini akan menggunakan Proxmox VE. Virtual space container pada penelitian ini akan memiliki spesifikasi sebagai berikut:

Tabel 1. Spesifikasi virtual space container.

\begin{tabular}{|c|l|c|}
\hline No & Nama Hardware & Spesifikasi \\
\hline 1 & Intel Xeon E5 Processor & 4 Core \\
\hline 2 & Memori & $2 \mathrm{~GB}$ \\
\hline 3 & Storage & $100 \mathrm{~GB}$ \\
\hline 4 & Network & Ethernet Gbits \\
\hline
\end{tabular}




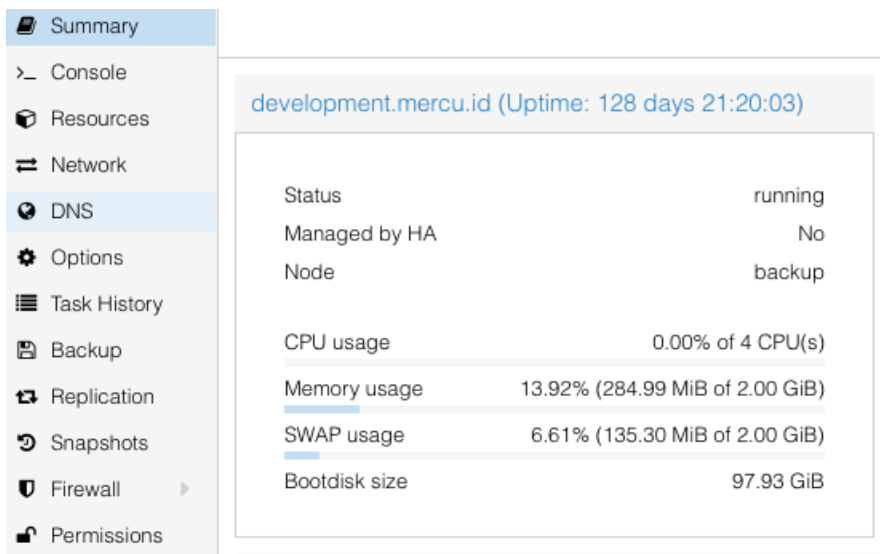

Gambar 2. Spesifikasi Virtual Space Container pada ProxmoxVE.

\subsection{Pengujian Web Server}

Pengujian web server menggunakan Apache Bench dilakukan melalui bash dengan memberikan beban request bertahap mulai dari range 100, 1000, 10000, sampai 100000 request. Dari beban request yang diberikan kepada web server tersebut kemudian kita dapat melihat berapa lama waktu yang dihabiskan web server untuk menyelesaikan request tersebut.

\subsubsection{Pengujian Apache Web Server}

Pengujian pertama dilakukan pada Apache web server, dengan beban request 100 sampai 100000 yang diberikan secara bertahap.

a. 100 request

Perintah bash Apache Bench yang dieksekusi:

"ab -n 100 -c 100 http://103.58.111.134/"

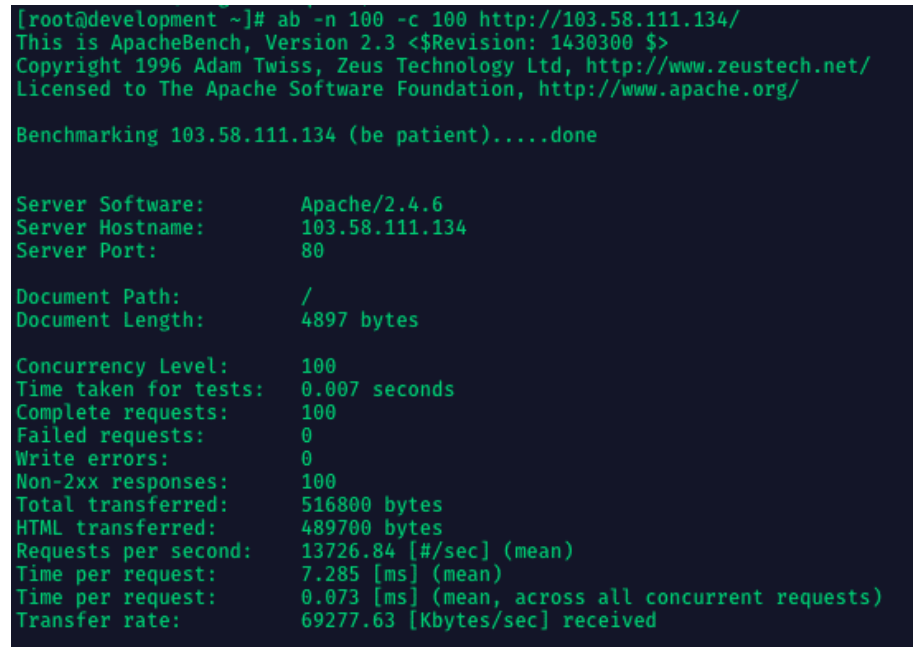

Gambar 3. Hasil pengujian Apache 100 request.

Dari hasil pengujian pada Gambar 3 dapat kita lihat bahwa Apache web server dalam mengeksekusi 100 request membutuhkan waktu 0.007 seconds.

b. 1000 request

Perintah bash Apache Bench yang dieksekusi:

"ab -n 1000 -c 100 http://103.58.111.134/"

Analisis Performansi Antara Apache \& Nginx Web Server dalam Menangani Client Request (Albert Yakobus Chandra) 


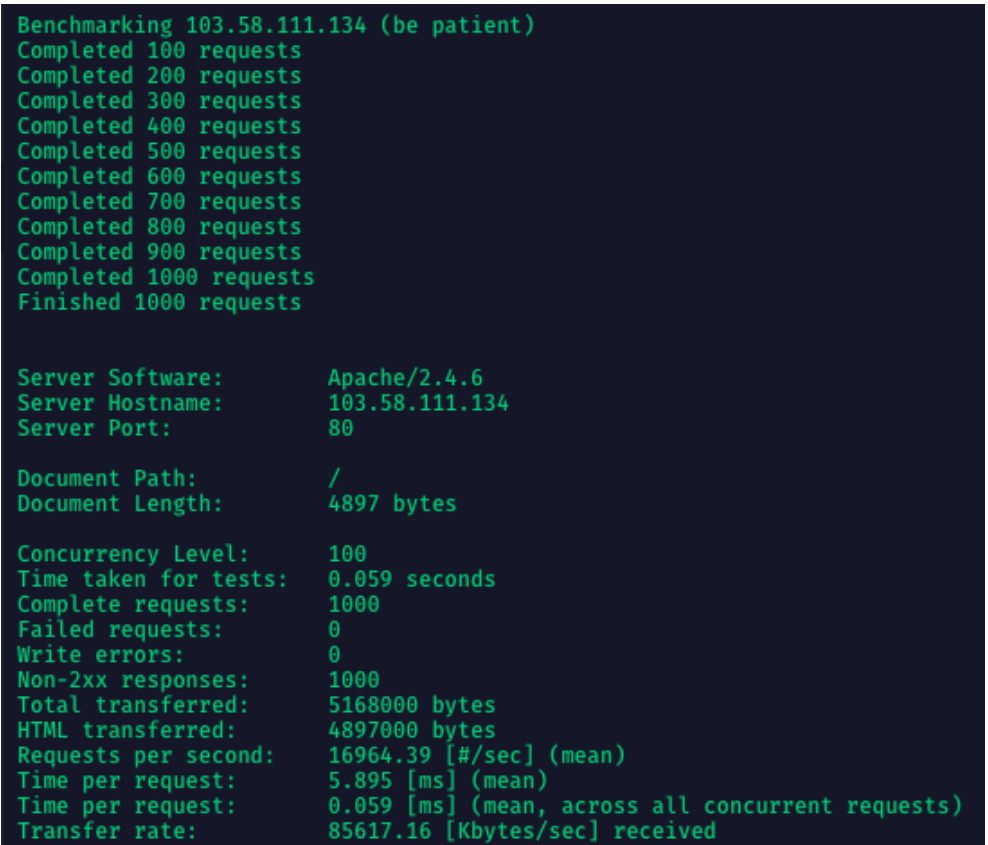

Gambar 4. Hasil pengujian Apache 1000 request.

Dari hasil pengujian pada Gambar 4 dapat kita lihat bahwa Apache web server dalam mengeksekusi 1000 request membutuhkan waktu 0.059 seconds.

c. 10000 request

Perintah bash Apache Bench yang dieksekusi:

"ab -n 10000 -c 100 http://103.58.111.134/"

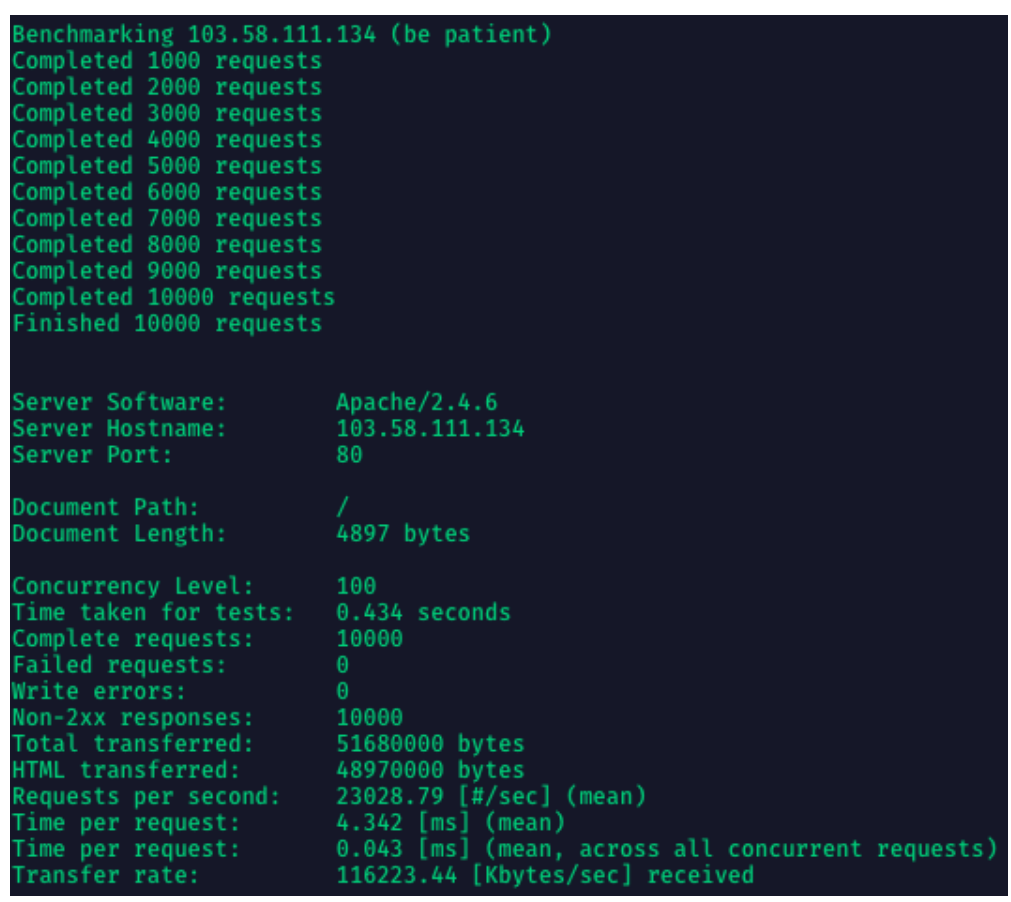

Gambar 5. Hasil pengujian Apache 10000 request.

Dari hasil pengujian pada Gambar 5 dapat kita lihat bahwa Apache web server dalam mengeksekusi 10000 request membutuhkan waktu 0.434 seconds. 
d. 100000 request

Perintah bash Apache Bench yang dieksekusi:

"ab -n 100000 -c 100 http://103.58.111.134/"

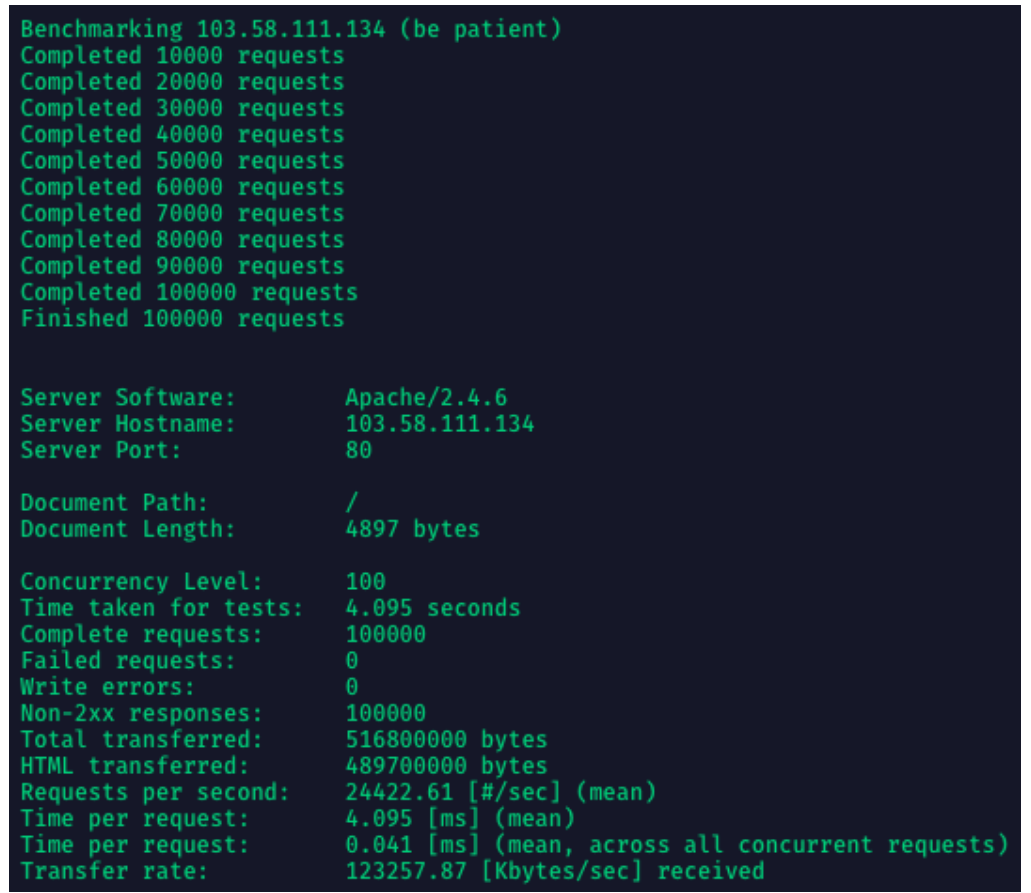

Gambar 6. Hasil pengujian Apache 100000 request.

Dari hasil pengujian pada Gambar 6 dapat kita lihat bahwa Apache web server dalam mengeksekusi 100000 request membutuhkan waktu 4.095 seconds.

\subsubsection{Pengujian Nginx Web Server}

Pengujian pertama dilakukan pada Nginx web server, dengan beban request 100 sampai 100000 yang diberikan secara bertahap.

a. 100 request

Perintah bash Apache Bench yang dieksekusi:

"ab -n 100 -c 100 http://103.58.111.134/"

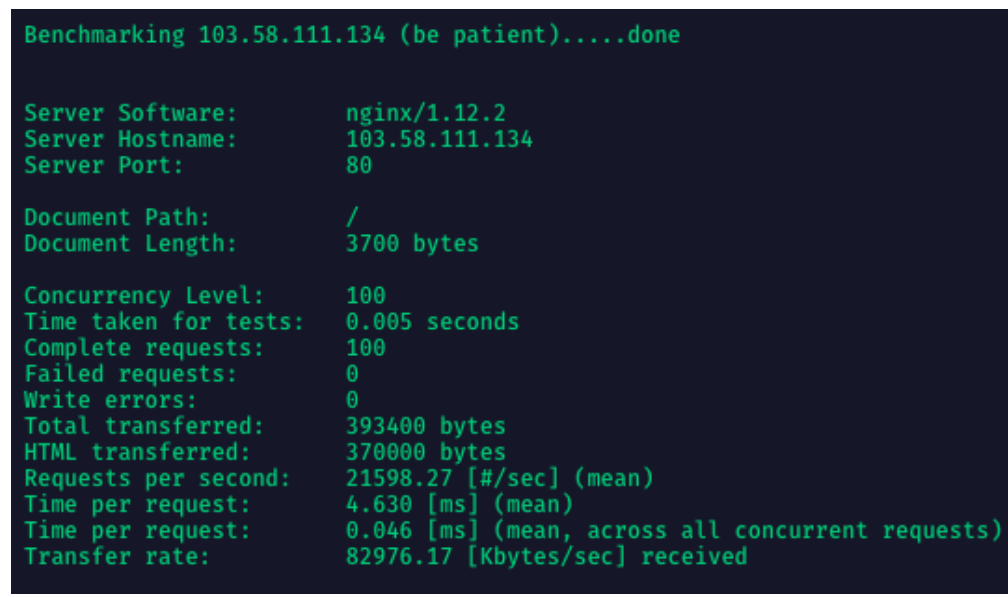

Gambar 7. Hasil pengujian Nginx 100 request.

Dari hasil pengujian pada Gambar 7 dapat kita lihat bahwa Nginx web server dalam mengeksekusi 100 request membutuhkan waktu 0.005 seconds.

Analisis Performansi Antara Apache \& Nginx Web Server dalam Menangani Client Request (Albert Yakobus Chandra) 
b. 1000 request

Perintah bash Apache Bench yang dieksekusi:

"ab -n 1000 -c 100 http://103.58.111.134/"

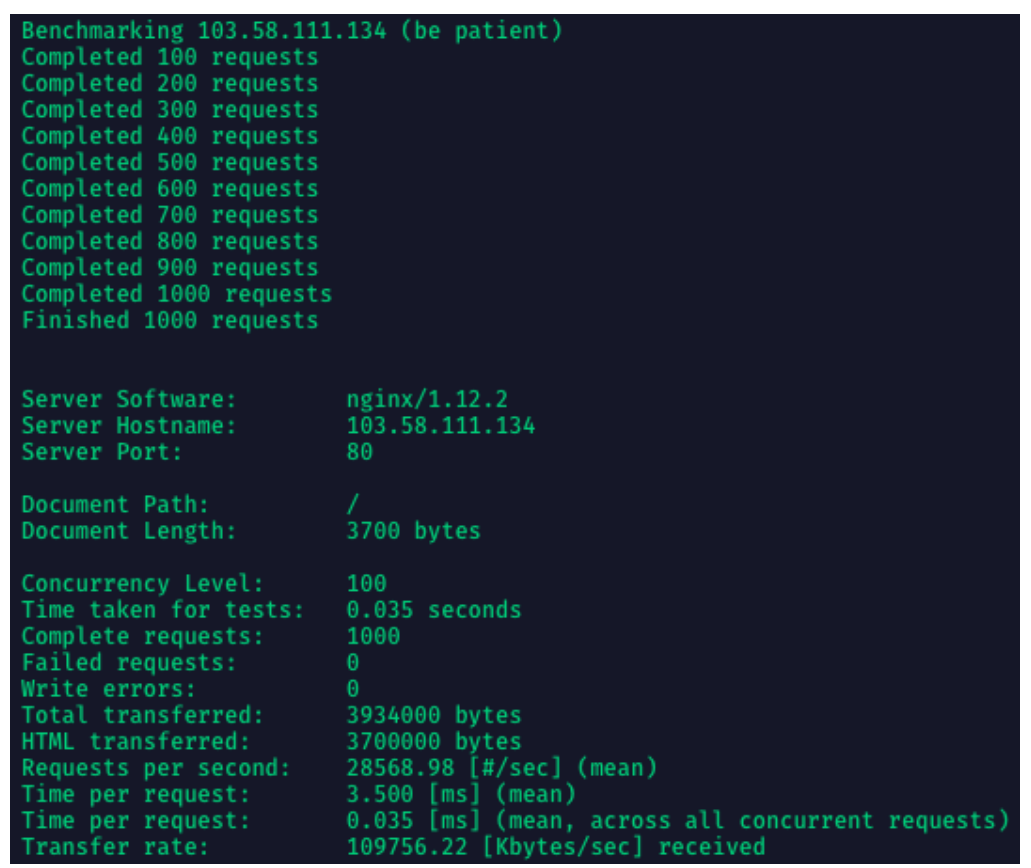

Gambar 8. Hasil pengujian Nginx 100 request.

Dari hasil pengujian pada Gambar 8 dapat kita lihat bahwa Nginx web server dalam mengeksekusi 1000 request membutuhkan waktu 0.035 seconds.

c. 10000 request

Perintah bash Apache Bench yang dieksekusi:

"ab -n 10000 -c 100 http://103.58.111.134/"

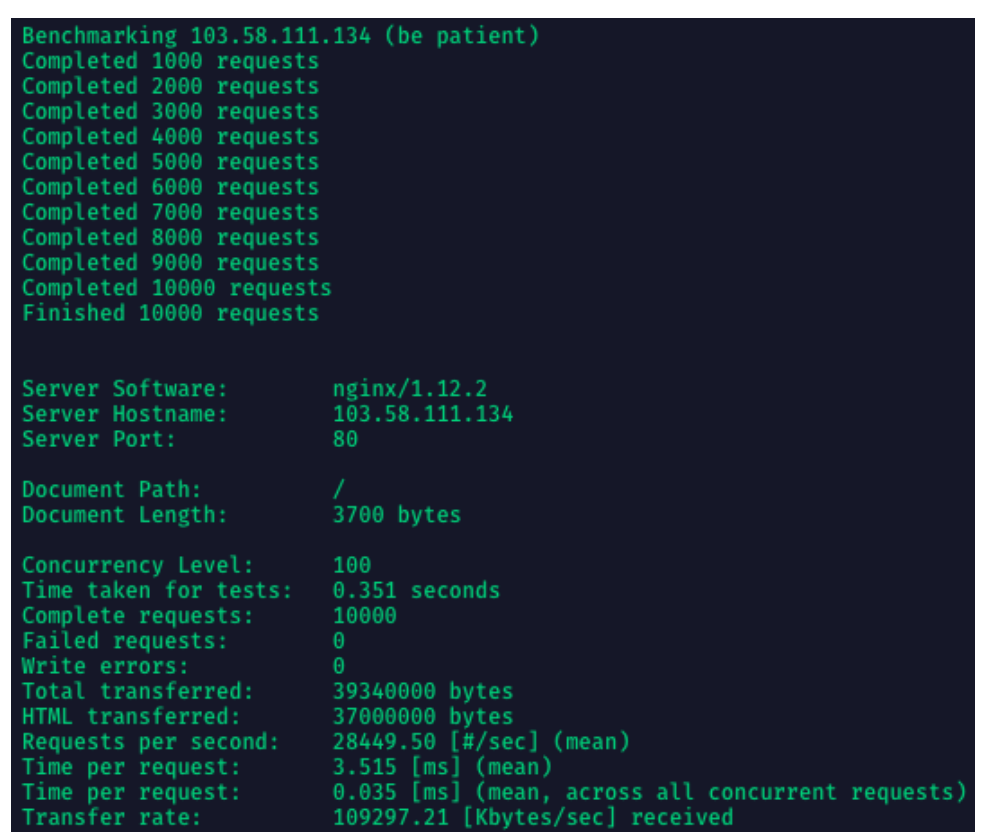

Gambar 9. Hasil pengujian Nginx 100 request. 
Dari hasil pengujian pada Gambar 9 dapat kita lihat bahwa Nginx web server dalam mengeksekusi 10000 request membutuhkan waktu 0.351 seconds.

d. 100000 request

Perintah bash apache bench yang dieksekusi:

"ab -n 100000 -c 100 http://103.58.111.134/"

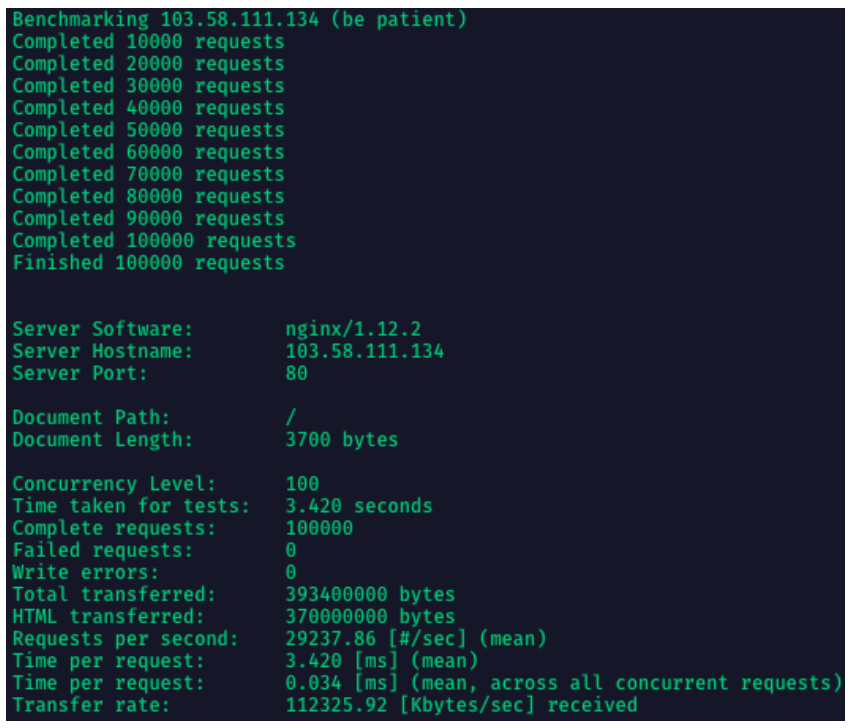

Gambar 10. Hasil pengujian Nginx 100 request.

Dari hasil pengujian pada gambar 10 dapat kita lihat bahwa nginx web server dalam mengeksekusi 100000 request membutuhkan waktu 3.420 seconds.

\subsection{Analisis Hasil}

Hasil pengujian yang dilakukan terhadap kedua web server yaitu Apache dan Nginx dapat dilihat pada tabel hasil pengujian berikut:

Tabel 2. Waktu yang digunakan antara Apache dan Nginx.

\begin{tabular}{ccc}
\hline Web Server & Jumlah Request & Waktu yang digunakan (Seconds) \\
\hline \multirow{3}{*}{ Apache } & 100 & 0,007 \\
\cline { 2 - 3 } & 1000 & 0,059 \\
\cline { 2 - 3 } & 10000 & 0,434 \\
\hline \multirow{3}{*}{ Nginx } & 100000 & 4,095 \\
& 100 & 0,005 \\
\cline { 2 - 3 } & 1000 & 0,035 \\
\cline { 2 - 3 } & 10000 & 0,351 \\
\hline
\end{tabular}

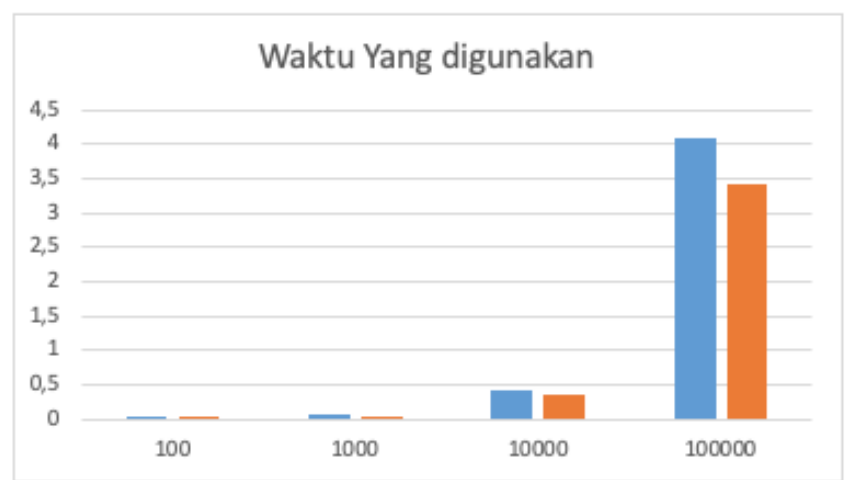

Gambar 11. Chart Hasil Pengujian. Biru:Apache, Orange: Nginx.

Analisis Performansi Antara Apache \& Nginx Web Server dalam Menangani Client Request (Albert Yakobus Chandra) 
Dari Tabel 2 hasil pengujian dan chart pada Gambar 11 dapat kita lihat bahwa Nginx memiliki rata-rata waktu penyelesaian request yang lebih cepat dibandingkan dengan Apache sehingga dapat diambil kesimpulan bahwa performansi Nginx lebih baik dibandingkan dengan Apache dalam hal menangani client request.

\section{Kesimpulan}

Penelitian ini dilakukan dengan harapan dapat memberikan hasil uji performansi pada kedua web server yang populer digunakan saat ini yaitu Apache dan Nginx dalam menangani client request. Dari hasil uji yang dilakukan pada kedua web server tersebut menujukan bahwa Nginx memiliki rata-rata waktu penyelesaian request yang lebih cepat dibandingkan dengan Apache. Hasil ini didapatkan setelah proses pengujian dengan jumlah request mulai dari 100 sampai 1000000 dengan menggunakan tool Apache Bench.

Berdasarkan atas hasil uji yang didapatkan pada penelitian ini, maka diharapkan dapat memberikan masukan sebagai pilihan web server mana yang akan digunakan nantinya dalam membangun sebuah sistem website yang akan digunakan jika website tersebut akan menangani banyaknya client request. Kemudian berdasarkan hasil yang diperoleh maka penelitian ini dapat dilanjutkan dengan menguji performansi kedua web server tersebut dari aspek lain seperti concurrency level dan jumlah url diakses pada waktu yang bersamaan.

\section{Daftar Pustaka}

[1] K. Claffy, G. Miller, and K. Thompson, "The Nature of the Beast: Recent Traffic Measurements from an Internet Backbone," Int. Netw. Conf. '98, Geneva, Switzerland, Jul 1998, Internet Soc., vol. et'98, no. February 2016, pp. 21-24, 1998.

[2] K. Kant and Y. Won, "Server capacity planning for Web traffic workload," IEEE Trans. Knowl. Data Eng., vol. 11, no. 5, pp. 731-747, 1999.

[3] G. Li, H. Zheng, and G. Li, "Building a secure web server based on OpenSSL and apache," Proc. Int. Conf. E-bus. E-Government, ICEE 2010, pp. 1307-1310, 2010.

[4] "Seven of the best open source web servers for your organisation | Gallery | Computerworld UK." [Online]. Available: https://www.computerworlduk.com/galleries/open-source/best-open-sourceweb-servers-for-your-organisation-3655327/. [Accessed: 12-Feb-2019].

[5] “Apache vs. Nginx vs. Microsoft-IIS usage statistics, February 2019." [Online]. Available: https://w3techs.com/technologies/comparison/ws-apache,ws-microsoftiis,ws-nginx. [Accessed: 12Feb-2019].

[6] A. Aziz and T. Tampati, "Analisis Web Server untuk Pengembangan Hosting Server Institusi: Pembandingan Kinerja Web Server Apache dengan Nginx,” Multinetics, vol. 1, no. 2, p. 12, 2015.

[7] F. Adnan, "Analisis Perbandingan Performa Web Server Apache dan Nginx menggunakan Httperf pada VPS dengan Sistem Operasi CentOs," Stmik Amikom Yogyakarta, p. 6, 2016.

[8] Y. Hu, A. Nanda, and Q. Yang, "Measurement, analysis and performance improvement of the Apache Web server," 1999 IEEE Int. Performance, Comput. Commun. Conf. IPCCC 1999, pp. 261-267, 1999.

[9] X. Chi, B. Liu, Q. Niu, and Q. Wu, "Web load balance and cache optimization design based nginx under high-concurrency environment," Proc. - 2012 3rd Int. Conf. Digit. Manuf. Autom. ICDMA 2012, pp. 1029-1032, 2012.

[10] M. Data, M. Luthfi, and W. Yahya, "Optimizing single low-end LAMP server using NGINX reverse proxy caching,” Proc. - 2017 Int. Conf. Sustain. Inf. Eng. Technol. SIET 2017, vol. 2018-Janua, no. February, pp. 21-23, 2018.

[11] The CentOS Project, "CentOS,” 2019. [Online]. Available: https://www.centos.org/about/.

[12] Y. Tachibana, J. Kon, and S. Yamaguchi, "A study on the performance of web applications based on RoR in a highly consolidated server with container-based virtualization," Proc. - 2017 5th Int. Symp. Comput. Networking, CANDAR 2017, vol. 2018-Janua, pp. 580-583, 2018.

[13] N. S. Sukmadinata, Metode Penelitian Pendidikan. Bandung: Remaja Rosdakarya, 2009.

[14] M. Sholikhin et al., "Analisis Performansi Server Cluster Pada Load Balancing," pp. 1-8, 2016. 